\title{
Estrategias de disposición del suelo público: mercantilización e inflexiones del neoliberalismo urbano en Ciudad de Buenos Aires (2015-2018)
}

Strategies of Public Land Disposition: Commodification and Inflexions of Urban Neoliberalism in Buenos Aires (2015-2018)

Estratégias de disposição do solo público: mercantilização e inflexões do neoliberalismo urbano na Cidade de Buenos Aires (2015-2018)

Ivana Socoloff (Coord. $)^{*}$

Nicole Camji ${ }^{* *}$

Federico Montagna ${ }^{\star * *}$

María Agustina Peralta ${ }^{* \star \star \star}$

Yamila Lara Sahakian ${ }^{\star * \star * *}$

Recibido: 29 de septiembre de 2018

Aprobado: 31 de julio de 2019

Doi: https://doi.org/10.12804/revistas.urosario.edu.co/territorios/a.7286

Para citar este artículo:

Socoloff, I., Camji, N., Montagna, F., Peralta, A., \& Sahakian, Y. L. (2020). Estrategias de disposición del suelo público: mercantilización e inflexiones del neoliberalismo urbano en Ciudad de Buenos Aires (2015-2018). Territorios, (43), 1-24. https://doi.org/10.12804/revistas.urosario.edu.co/territorios/a.7286 * Investigadora IEALC-
UBA/Conicet/CCCoop
(Argentina). Correo
electrónico: ivisoc@gmail.
com. ORCID: http://orcid.
org/0000-0001-6675-
4372
**Universidadde Buenos
Aires (Argentina).Correo
electrónico: nicoleca-
mji@gmail.com. ORCID:
bttps://orcid.org/0000-
o002-6592-9393
*** Universidad de
Buenos Aires (Argenti-
na). Correo electrónico:
pmagustina@gmail.com.
ORCID: https://orcid.
org/0000-0001-8381-9203
****Universidad de
Buenos Aires (Argenti-
na).Correo electrónico:
monti93fede@gmail.com.
ORCID: bttps://orcid.
org/0000-0003-3039-
8825 
Palabras clave

Privatización de tierras; tierra pública; política urbana; urbanismo neoliberal.

Keywords

Land privatization; public land; urban policy; urban neoliberalism.

Palavras-chave

Privatização de terras; terra pública; politica urbana; urbanismo neoliberal.

territarias 43

\section{RESUMEN}

El presente artículo se enmarca en un estudio comparativo de los proyectos de concesión y privatización de suelo llevados adelante en la Ciudad de Buenos Aires desde 2015 a 2018. Nuestro objetivo es analizar las estrategias de disposición de tierra desplegadas por medio de la concesión y privatización en el ámbito de la Ciudad de Buenos Aires, reconstruyendo las racionalidades políticas que se articularon en torno a ellas y los dispositivos institucionales creados para viabilizarlas. Nuestro argumento central es que, inscriptos en discursos sobre la 'ociosidad' de los terrenos, se movilizan grandes superficies de suelo mediante la creación de dispositivos institucionales que profundizan la fragmentación presupuestaria y territorial, sustrayendo del ámbito legislativo sus atribuciones en la definición de usos del suelo. Intentamos abordar así las continuidades e inflexiones en el urbanismo neoliberal porteño. Adoptamos una estrategia metodológica basada en el análisis de documentos producidos por las autoridades.

\section{ABSTRACT}

This article is part of a comparative study of land concession and privatization projects carried out in the City of Buenos Aires from 2015 to 2018. Our goal is to analyze the land disposal strategies deployed by authorities through the concession and privatization in the City of Buenos Aires, reconstructing the political rationalities that were articulated around them and the institutional devices created to make them viable. Our central argument is that, inscribed in discourses about the 'idleness' of the land, large areas were mobilized through the creation of institutional devices that deepen the budgetary and territorial fragmentation, subtracting from the legislative scope its attributions in the definition of land uses. In doing so, we address the continuities and inflections in Buenos Aires' urban neoliberalism. We adopt a methodological strategy based on the analysis of documents produced by authorities.

\section{RESUMO}

O presente artigo enquadra-se em um estudo comparativo dos projetos de concessão e privatização de solo levados a cabo na Cidade de Buenos Aires desde 2015 a 2018. O nosso objetivo é analisar as estratégias de disposição de terra desenvolvidas por meio da concessão e privatização no âmbito da Cidade de Buenos Aires, reconstruindo as racionalidades políticas que se articularam em torno a elas e os dispositivos institucionais criados para viabilizá-las. Nosso argumento central é que, inscritos em discursos sobre a 'ociosidade' dos terrenos, se mobilizam grandes superfícies de solo mediante a criação de dispositivos institucionais que aprofundam a fragmentação orçamentária e territorial, subtraindo do âmbito legislativo suas atribuições na definição de usos do solo. Tentamos abordar assim as continuidades e inflexões no urbanismo neoliberal portenho. Adotamos uma estratégia metodológica baseada na análise de documentos produzidos pelas autoridades.

Ivana Socoloff, Nicole Camji, Federico Montagna, María A. Peralta, Yamila L. Sahakian 


\section{Introducción}

En este artículo nos proponemos analizar las estrategias de disposición de tierra pública en el ámbito de la Ciudad de Buenos Aires desde diciembre de 2015 (a partir de la asunción de Mauricio Macri a la Presidencia de la República Argentina) hasta el año 2018. En el análisis repararemos en los dispositivos institucionales por medio de las cuales se implementan dichas estrategias, y en las racionalidades de gobierno ${ }^{1}$ (Foucault, 2008) que las dotan de sentido. Nuestro estudio parte de la constatación de que en el período mencionado se han multiplicado las iniciativas de mercantilización y transferencia de terrenos de propiedad estatal hacia el sector privado en Argentina.

Nuestro argumento central en este artículo es que los proyectos de venta y concesión de parcelas públicas de la Ciudad de Buenos Aires, fundamentados por discursos referidos a la previa 'inacción' estatal en la política del suelo y la 'ociosidad' de los terrenos en cuestión, están movilizando grandes superficies de suelo mediante la creación de dispositivos institucionales diversos a los cuales se asigna la atribución de definir los usos del suelo, facultad que anteriormente correspondía al poder legislativo. De este modo, gracias a la transformación del funcionamiento de los mecanismos democráticos que tenían competencia en la disposición del patrimonio estatal, se ha articulado una nueva modalidad de mercantilización y privatización del suelo público, que en este trabajo pretendemos explicar.

Este fenómeno plantea continuidades y algunas inflexiones en los modos en que la gestión del suelo y el "urbanismo neoliberal" (Theodore et al., 2009) han tomado forma en la Ciudad de Buenos Aires. Al respecto, dos momentos en la historia argentina sobresalen como momentos en los que las autoridades se propusieron deshacerse de inmuebles de propiedad estatal: durante la dictadura militar (19761983) y en los primeros años de la década de 1990. Y si, por un lado, estos procesos se encuentran mayormente documentados para el período de la presidencia de Carlos Saúl Menem (1989-1999) (Clichevsky, 1996), mucho menos se conoce sobre los inmuebles vendidos, entregados, concesionados o apropiados por las autoridades militares durante la segunda mitad de la década de 1970 .

Entendemos que la especificidad de los procesos de mercantilización de suelo público que aquí estudiamos está constituida por el contexto global en el cual la tierra - tanto rural como urbana- es progresivamente percibida por los agentes financieros como un activo o asset class cuyo valor es necesario capturar. Posteriormente, abordaremos brevemente las estrategias de disposición del suelo público en la Ciudad de Buenos Aires en la década de los noventa, para luego entrar de lleno en el período que nos convoca: diciembre de 2015 a abril de 2018 , haciendo foco en dos elementos relevantes: a) los

na). Correo electrónico: yamilasahakian@gmail. com. ORCID: https://orcid. org/0000-0003-2541-7761

${ }^{1}$ Entendemos por racionalidades de gobierno las estrategias de gestión de lo social y lo subjetivo que son trazadas a partir de prácticas discursivas y extradiscursivas por parte de diversas autoridades que efectúan el ejercicio del poder (Foucault, 2008). De acuerdo con De Marinis (1999), las racionalidades gubernamentales suponen una concordancia de reglas, formas de pensar, procedimientos tácticos, conjunto de condiciones, bajo las cuales, en un momento dado, resulta posible percibir algo como un problema, tematizarlo como tal y generar alternativas prácticas de resolución de este, aun pese a las resistencias que pueda generar por parte de otros actores. El arte de gobierno en un período histórico determinado no debe ser pensado desde una perspectiva monolítica o estática; por el contrario, las racionalidades de gobierno son diversas y en ocasiones contradictorias, por lo que se ven continuamente transformadas, aun en un mismo tiempo y espacio.

\section{territarias 43}


${ }^{2}$ Al respecto, el debate intelectual se ba orientado en un primer momento a la denuncia de esta ola de transferencias, muchas veces concertadas entre agentes privados con capacidades diversas de enfrentar esas transacciones. Un poco más recientemente, otras investigaciones han problematizado esta adquisición "a distancia" de porciones de tierra atravesadas por lógicas locales, mostrando las contradicciones de estos procesos donde los locales no serian meras "victimas" de una nueva forma de colonialismo, sino agentes activos en estas dinámicas (Pedersen, 2016), participando de la politica internacional por medio de, por ejemplo, titulos de propiedad cuestionables, capacidad limitada de implementación de las transferencias, terrenos atravesados por conflictos bélicos, etc.

\section{territarias 43}

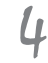

dispositivos institucionales implementados para llevar adelante la mercantilización y movilización de suelo público; y b) las racionalidades gubernamentales que orientan contradictoriamente el diseño de las tecnologías antes mencionadas. En cuanto al punto a), distinguiremos dos mecanismos de enajenación de tierras públicas implementadas en el período estudiado: por un lado, la mercantilización de terrenos pertenecientes al Gobierno de la Ciudad de Buenos Aires (GCBA) por medio del tratamiento de proyectos en la Legislatura; y, por otro lado, la enajenación de parcelas pertenecientes al Estado Nacional ubicadas en la ciudad capital por medio de la acción de la Agencia de Administración de Bienes del Estado (AABE). Elaboraremos esta descripción a partir del análisis de decretos, resoluciones y transcripciones de debates legislativos de la Ciudad de Buenos Aires.

En el tercer apartado, analizaremos las racionalidades de gobierno que orientan (de forma contradictoria) el diseño de las tecnologías que se articulan en torno a los proyectos de concesión y privatización de terrenos públicos en la Ciudad de Buenos Aires. Buscaremos mostrar que estas argumentaciones, si bien no todas resultan novedosas, se integran a los dispositivos de mercantilización y movilización de suelo público presentes en el período estudiado dotándolos de fundamentación y sentidos. Abordaremos las racionalidades de gobierno fundamentalmente mediante el análisis de contenido de las intervenciones en los debates legislativos en torno a los proyectos de concesión y enajenación de tierras de la Ciudad de Buenos Aires.

\section{Disposición de suelo e inflexiones del neoliberalismo urbano}

En los últimos diez años, diversos investigadores internacionales se han enfocado en el estudio de los recientes procesos de privatización de tierra pública. $\mathrm{Si}$, por un lado, una serie de investigaciones se abocó al análisis de las land-grabbing, es decir, a la masiva adquisición de grandes porciones de tierra por parte de empresas transnacionales, individuos o aun gobiernos, muchas veces ubicadas en localidades remotas respecto al lugar donde se toma la decisión, otros investigadores hacen referencia a los "nuevos cercamientos" de tierra urbana en las principales ciudades del mundo (Christophers, 2018). Dicha transferencia ha sido asociada a fenómenos de desposesión vinculados con el neoliberalismo y la financiarización (Christophers, 2018; Pedersen \& Buur, 2016; Shatkin, 2017; Whiteside, 2019) que han convertido a la tierra en un nuevo asset class, es decir, un activo/recurso valorado y valorizado por los inversores especializados. ${ }^{2}$

Así mismo, y siguiendo la afirmación popularizada de Harvey según la cual la tierra se convierte en un "activo puramente financiero" (1982, p. 21), numerosos investigadores han centrado su atención en cómo la financiarización ha profundizado (o mutado) al neoliberalismo urbano o 
al empresarialismo municipal (Harvey, 1989). Para ellos, las agencias estatales no solo han facilitado el proceso de mercantilización y financiarización de la tierra (Christophers, 2017; Fields, 2013), sino que también - en los casos extremos- se han convertido ellas mismas en agentes financieros activos que especulan con la propiedad pública mediante mecanismos institucionales, legales, contables, etc. (Beswick \& Penny, 2018).

De forma tal que, podemos afirmar, estamos ante un proceso multiescalar y trasnacional (Brenner, 2004) de puesta a disposición de tierras para el desarrollo de emprendimientos urbanos, para la obtención de renta o simplemente para conformar un stock de tierras en manos de inversores internacionales. Dicho fenómeno existente hace décadas parece haberse intensificado globalmente luego de la crisis de 2008 como respuesta a una búsqueda de activos reales, supuestamente más seguros para los inversores (Christophers, 2017), dando lugar a mutaciones en el "urbanismo neoliberal" del que daba cuenta la bibliografía internacional cuando terminaba la década de los noventa (Theodore et al., 2009).

Ahora bien, en economías donde los procesos de financiarización en el segmento inmobiliario no son generalizados o encuentran varios límites (Fernández \& Aalbers, 2019), como es sin duda el caso argentino (Socoloff, 2019), la venta de terrenos públicos responde muchas veces a los intentos de las autoridades de impulsar la construcción en momentos de vulnerabilidad económica producidas por el propio proceso de financiarización. Allí, y como relatan otras investigaciones, el papel de las autoridades nacionales y locales es clave, junto con el de los desarrolladores locales, quienes, en alianza (o en disputa) con los inversores internacionales, se apropian de las tierras puestas a disposición por parte de las autoridades (Socoloff, 2019).

Para analizar estas dinámicas, sin embargo, partimos de elementos aún más básicos en el marco de este artículo. Por un lado, entendemos que la tierra es un bien imprescindible para la supervivencia humana, que posee materialidad y localización, y que es pasible de convertirse en un "recurso" (¿natural?) solamente por medio de la coconstrucción de una serie de dispositivos de inscripción que son ellos mismos parte integral del proceso de "ensamblaje" (Murray Li, 2014). Medirla, localizarla, mapearla, cercarla, valuarla, trabajarla, etc., son todas tareas de este proceso que regula y gobierna la ocupación y distribución de las personas en el espacio. Ahora bien, como nos aclara Murray Li (2014), los ensamblajes no son estables, sino que se encuentran en disputa: es decir, son estabilizados mediante diversos mecanismos que incluyen sustancias, tecnologías, discursos y prácticas. Así, la tierra puede ser técnicamente mercantilizable, pero no plenamente, ya que es condición para la vida. 
${ }^{3}$ Nos referimos a servicios tales como las redes de subterráneos y ferrocarriles, el Mercado de Hacienda, el Hipódromo, el Zoológico de Buenos Aires, los casinos y bingos.

${ }^{4}$ La Costanera Norte es uno de los corredores que bordea la orilla norte del rio de la Plata, que cuenta en la actualidad con espacios verdes, espacios comerciales, artísticos, bailables, recreativos $y$ deportivos, asi como con la Ciudad Universitaria y la Reserva Ecológica Costanera Norte.

territarias 43
Recuperando entonces la noción de la tierra que deviene 'recurso' que debe ser 'explotado' en contextos de profundización/mutación del neoliberalismo urbano a la luz de la financiarización (del interés creciente hacia la tierra en tanto asset class), es que nos interesa particularmente analizar las estrategias de disposición de tierras y bienes inmuebles por parte de diversas autoridades en Argentina en el período 2015-2018. Al respecto algunas de las grandes preguntas que orientan este texto son: ¡ cómo fue concebida la tierra pública urbana en los recientes discursos y prácticas de las autoridades? ¿Qué dispositivos se crearon para disponer de ella? Dentro de los límites de esas preguntas, no abordaremos aquí el conjunto de disputas que enmarcan esos procesos, sino que nos enfocaremos específicamente en: 1) la descripción breve de algunas tecnologías y técnicas que han permitido la creación de instituciones parademocráticas en el seno del gobierno local y nacional, que se encuentran en tensión con el poder legislativo y con la normativa vigente; y 2) el análisis de las racionalidades que orientan contradictoriamente el diseño de las tecnologías antes mencionadas.

\section{La disposición de la tierra en Buenos Aires en los noventa: breve consideración}

Con la reforma del Estado y el proceso de privatizaciones en Argentina durante los años noventa, gran parte de los servicios públicos y de otros servicios urbanos ${ }^{3}$ de Buenos Aires pasaron a manos privadas: en este período, un gran número de inmuebles pertenecientes a organismos estatales (como las Fuerzas Armadas, el Banco Hipotecario o las compañías ferroviarias) y a empresas públicas privatizadas fueron transferidas a grupos económicos y a desarrolladores privados. Así mismo, se concesionaron plazas y terrenos públicos (como los predios ubicados sobre la Costanera Norte $)^{4}$ y otras políticas controvertidas como la permisión de instalación de áreas comerciales en instituciones educativas públicas, llamadas coloquialmente 'escuelas shopping'.

De acuerdo con Pírez (2006), el fenómeno que tuvo lugar en la Región Metropolitana de Buenos Aires en los años noventa fue de privatización urbana, proceso que ha tenido un carácter doble: por un lado, la privatización de la producción urbana (es decir, la subordinación de las lógicas de urbanización a la dinámica de acumulación del capital privado); y, por el otro, la privatización de los productos urbanos (es decir, la exclusión del consumo de bienes y servicios urbanos a segmentos importantes de la población) (pp. 32-33).

En el mismo período, se produjo a su vez una expansión de la tierra urbanizable como efecto de la construcción de autopistas y de la conversión en uso residencial de predios anteriormente inundables o sin servicios urbanos a partir de la aplicación de tecnologías por parte de los desarrolladores privados (Cravino et al., 2000; 
Torres, 2000). A su vez, a lo largo de la década de los noventa se introdujeron excepciones y modificaciones parciales y generales al Código de Planeamiento Urbano, lo cual amplió las posibilidades de los desarrolladores de captar la renta del suelo (Clichevsky, 1996; Socoloff, 2015). ${ }^{5}$

Para llevar adelante estas privatizaciones, algunos dispositivos institucionales novedosos fueron creados, entre los que se destacaron las 'corporaciones' (Corporación Puerto Madero y Corporación Sur), que permitieron, con diferencias entre sí, la gestión de amplias superficies de suelo sorteando algunos "obstáculos" institucionales. ${ }^{6}$ Sin embargo, con la sanción de la nueva constitución y la autonomización de la ciudad durante la segunda mitad de la década de los noventa, se introdujeron algunas limitaciones y nuevos requisitos a los cambios de normativas de usos del suelo y a las privatizaciones de bienes públicos, como fueron las nuevas mayorías legislativas, los procesos de doble lectura, los requisitos ambientales, entre otros (Ciccolella \& Mignaqui, 2008; Mignaqui, 2012).

Todo lo cual, si bien permitió desacelerar parcialmente algunos de los efectos de la privatización y mercantilización del suelo en el interior de la ciudad de Buenos Aires, ${ }^{7}$ no impidió que durante las décadas siguientes proliferaran la "verticalización" y la suburbanización residencial (Ciccolella \& Vecslir, 2012), y la normativa "facilitadora" de emprendimientos inmobiliarios en toda la Región
Metropolitana de Buenos Aires (Guevara, 2013; Socoloff, 2013a), especialmente durante el ciclo expansivo de la economía 2002-2011 (Baer, 2011; Baer \& Kauw, 2016; Del Río et al., 2014).

Esta política urbana se inscribió en un discurso (aún presente en la actualidad) en torno a la necesidad de 'modernizar la ciudad' favoreciendo la participación del sector privado, y ubicando al Estado en la posición de facilitar y promover la actividad económica de estos capitales, regulando tan solo algunos aspectos del gobierno urbano. Como presentaremos a continuación, los procesos observables en el período analizado pueden ser entendidos como una continuidad del fenómeno de privatización urbana originada en décadas anteriores, aunque por medio de mecanismos novedosos que constituyen su especificidad.

\section{La mercantilización de terrenos del GCBA por medio de proyectos legislativos}

Analizaremos, en primer lugar, las estrategias orientadas a la mercantilización de terrenos pertenecientes al Gobierno de la Ciudad por medio del tratamiento de proyectos parlamentarios en la Legislatura, que fueron aprobados entre diciembre de 2015 y abril de 2018 (figura 1). Se trata de once proyectos que si bien en una primera instancia fueron promovidos por el poder ejecutivo de la ciudad (encabezado por el jefe de gobierno, Horacio Rodríguez
${ }^{5}$ Sobre esta temática, véase Socoloff (2015).

' Al respecto, ver Garay (2004, 2007) y Mignaqui (2010).

7 Sobre algunos conflictos especificos en los que estas normativas dificultaron la capacidad de los desarrolladores en la ciudad de llevar adelante sus emprendimientos a pesar del acuerdo de autoridades nacionales y locales, véase el caso de IRSA (Socoloff, 2013a).

territarios 43 
${ }^{8}$ En 2015, el partido Unión PRO (alianza politica de centro-derecha surgida en 2007 y liderada por el ex presidente de Argentina, Mauricio Macri) obtuvo 15 bancas, que se sumaron a las otras 13 que no renovaban, obteniendo un total de 28. Dos años después, obtuvieron 6 nuevas bancas, sumando 34 (sobre un total de 60) legisladores en el bloque parlamentario que integraba.

9 Corredor vial de 7,1 kilómetros de extensión ubicado en la zona portuaria de la ciudad, cuya obra inició en enero de 2017 y fue inaugurado en mayo de 2019.

${ }^{10}$ La Corporación Buenos Aires Sur es una sociedad del Estado creada en el año 2000 con la potestad de generar relaciones $y$ realizar convenios con el sector privado en pos del desarrollo social y económico de la zona sur de la Ciudad de Buenos Aires.

${ }^{11}$ La Corporación Antiguo Puerto Madero es una sociedad anónima del Estado creada en 1989, a la cual le fueron cedidos los terrenos del barrio de Puerto Madero (área portuaria cercana a la zona central de la ciudad) a fin de llevar adelante su desarrollo urbanístico y reconversión.

territarios 43
Larreta) con la intención de sancionarlos por decreto, finalmente fueron aprobados en el ámbito legislativo. Así mismo, si bien la mayor parte de los terrenos públicos a los que refieren estos once proyectos habían sido objeto de intentos anteriores de enajenación o concesión previo a diciembre de 2015 , recién a partir de entonces se resolvió que se trabajasen en el recinto legislativo local, en buena medida gracias a la composición favorable al partido gobernante. ${ }^{8}$

Consideramos destacable el hecho de que la mayor parte de estos once proyectos incluyen precisiones acerca del destino de los fondos que ingresarán al Estado local con la enajenación o concesión de los terrenos, elemento que previamente no se incluía en las normativas: por ejemplo, el proyecto de venta de la Manzana IQ en el barrio de Puerto Madero dispone que los montos generados por su enajenación serían destinados a la construcción del Paseo del Bajo; ${ }^{9}$ o el proyecto de venta vía corporación de terrenos del Parque de la Ciudad para la construcción de la Villa Olímpica y el financiamiento de las obras de reurbanización de la Villa 20. Entendemos que el hecho de que estos proyectos incluyeran una disposición específica de lo recaudado hacia obras de interés público operó como argumento a favor de su aprobación en el recinto legislativo, opacando en algunos casos ciertas controversias en torno a la mercantilización de terrenos públicos. Igualmente, observamos una fragmentación presupuestaria como la que refiere Fix (2012), ya que, al ordenar la inversión de los montos recaudados en obras o entidades determinados por la propia normativa, se garantizaría así el 'autofinanciamiento' de otros proyectos urbanos (figura 1).

Algunos de estos proyectos dispusieron que la enajenación de los terrenos fuera gestionada por instituciones o entidades de gestión con participación del Estado local y del sector privado. En algunos casos, se dispuso la creación de nuevas instituciones con articulación público-privadas para concretar la venta de los terrenos y la gestión de los emprendimientos: es el caso de la venta de terrenos ubicados en el Autódromo de la Ciudad por vía de un fideicomiso financiero a 30 años (cuyo directorio está integrado por el Gobierno de la Ciudad, el Banco Ciudad, desarrolladores y entidades del automovilismo); o el proyecto de venta de Tiro Federal por medio de una agencia autorizada por la Legislatura. En otros casos, la enajenación de los terrenos fue encargada a organismos de participación público-privada ya existentes creados entre fines de los años ochenta y el año 2000, como los proyectos de venta de parcelas del Parque de la Ciudad para la creación de la Villa Olímpica por medio de la Corporación Buenos Aires Sur, ${ }^{10}$ o la venta de los terrenos de Empalme Norte y Manzana IQ a través de la Corporación Puerto Madero. ${ }^{11}$

A su vez, algunos de estos proyectos fueron encuadrados dentro de la política de distritos económicos en la Ciudad de 
Figura 1. Mapa de proyectos sobre terrenos en CABA aprobados por la Legislatura (dic. 15-dic. 17)

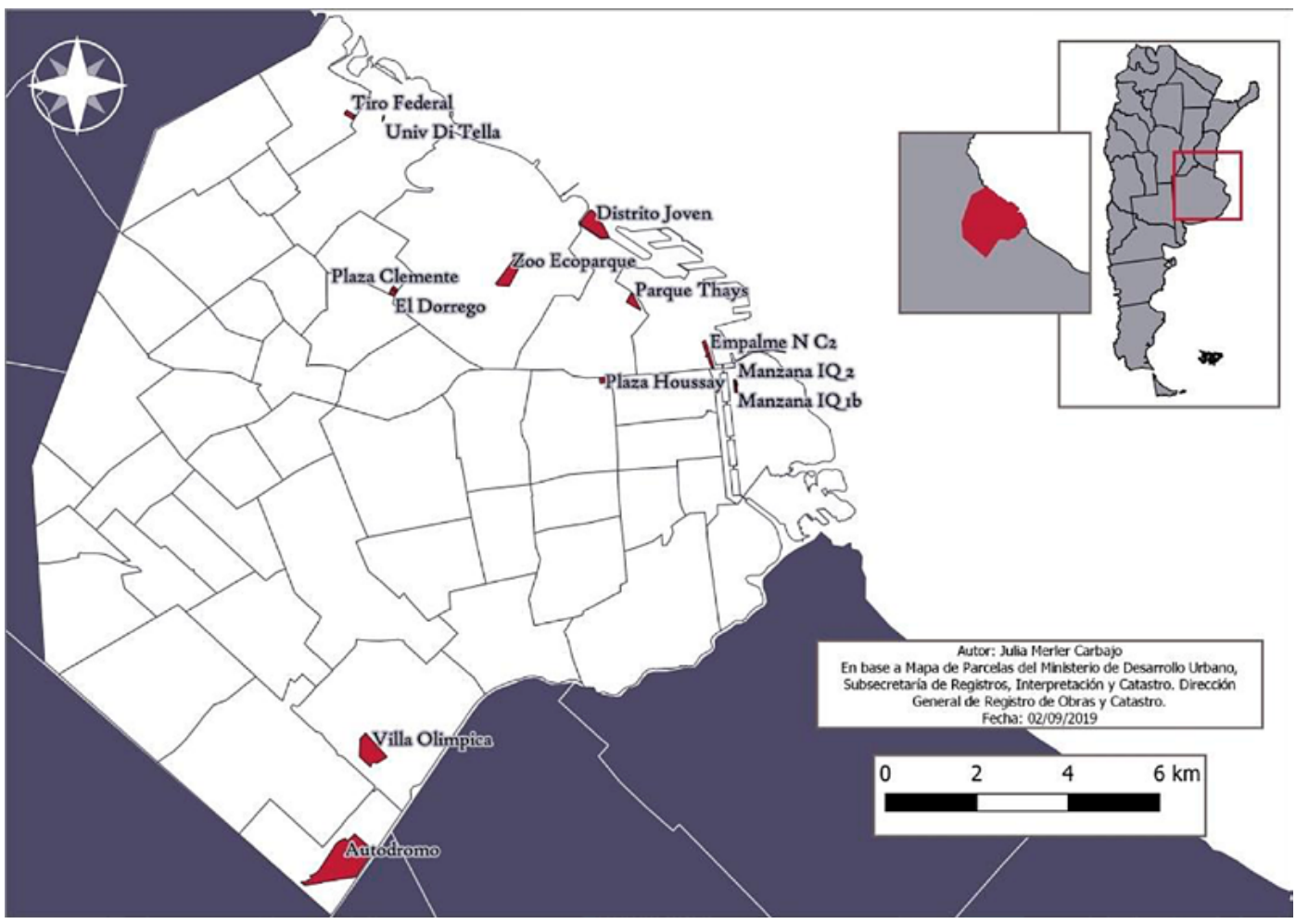

Fuente: elaboración de los autores con base en la normativa nacional y local.

Buenos Aires, originada en los primeros años de la década de 2000 y profundizada a partir del año $2008 .{ }^{12}$ La política de distritos busca promover la radicación de empresas especializadas en una misma rama en un espacio territorial delimitado (en la mayor parte de los casos, en barrios con bajo dinamismo económico), por medio de beneficios como exenciones impositivas o infraestructura especializada en el sector que se busca atraer (Arqueros \& González,
2017). Por ejemplo, se destaca por un lado el proyecto de creación del Distrito Joven, que consistió en la concesión de grandes extensiones de espacio público en la Costanera Norte de la Ciudad de Buenos Aires para favorecer la instalación de locales gastronómicos, bares y boliches bailables; por otra parte, los proyectos de la Villa Olímpica y el Autódromo fueron encuadrados dentro del Distrito del Deporte, creado en 2014.
${ }^{12}$ Respecto a la politica de distritos, pueden verse los articulos organizados en el número 7 de la revista Quid, 16, jun.-nov. 2017. territarias 43 
${ }^{13}$ Proyecto de reconversión del terreno del ex-Zoológico de Buenos Aires en un parque abierto al público orientado a la educación ambiental.

\section{territarias 43}

Finalmente, en algunos de estos proyectos (tabla l) se destaca la presencia de pedidos de 'contraprestaciones' económicas, sociales o culturales a cambio de la concesión o venta de terrenos públicos. Por ejemplo, mientras que el permiso de uso de un terreno público a la Universidad Di Tella (entidad educativa privada) exige una contraprestación de becas a empleados del poder ejecutivo y el uso por parte de los vecinos de un sector del predio mediando una autorización, los cánones de la concesión del Zoológico de Buenos Aires incluyen la condición de sostenimiento del patrimonio y el desarrollo del Ecoparque. ${ }^{13}$ Sin duda, estas contraprestaciones implican la fragmentación del suelo urbano en zonas o regiones, donde se pretende construir una 'sinergia' entre las obras realizadas, o bien entre ellas y los usos preexistentes del suelo.

Tabla 1. Proyectos sobre terrenos en CABA aprobados por la Legislatura (dic. 2015 a abr. 2018)

\begin{tabular}{|c|c|c|}
\hline Caso & Tipo & Instrumento y destino de los fondos recaudados \\
\hline Tiro Federal & $\begin{array}{l}\text { Venta (megaem- } \\
\text { prendimiento) }\end{array}$ & $\begin{array}{l}\text { - Venta vía creación de agencia con autorización de la Legislatura. } \\
\text { - Parte de lo recaudado será destinado a la urbanización de la } \\
\text { Villa } 31 \text {. } \\
\text { - Se licitará parte del terreno para financiar el resto de la obra. }\end{array}$ \\
\hline Villa Olímpica & $\begin{array}{l}\text { Venta (megaem- } \\
\text { prendimiento) }\end{array}$ & $\begin{array}{l}\text { - Venta vía corporación. } \\
\text { - El } 50 \% \text { de los fondos serán destinados a proyectos de la } \\
\text { comuna } 8 \text {. } \\
\text { El } 50 \% \text { serán destinados para la urbanización de la Villa } 20 \text {. } \\
\text { La desafectación se transfiere al Instituto de la Vivienda de la } \\
\text { Ciudad; los predios alojamiento, a los atletas olímpicos. } \\
\text { - Los predios serán destinados a venta de viviendas para vecinos } \\
\text { de la comuna } 8 \text {. }\end{array}$ \\
\hline Autódromo & $\begin{array}{l}\text { Venta (megaem- } \\
\text { prendimiento) }\end{array}$ & $\begin{array}{l}\text { - Venta vía creación de fideicomiso financiero a } 30 \text { años. } \\
\text { - Directorio para gestionar los bienes (Gobierno de la Ciudad, } \\
\text { Banco Ciudad, entidades del automovilismo, desarrolladores). }\end{array}$ \\
\hline $\begin{array}{l}\text { Empalme Norte } \\
\text { (Catalinas 2) }\end{array}$ & Venta & $\begin{array}{l}\text { - Enajenación por la Corporación Antiguo Puerto Madero. } \\
\text { - Subasta a cargo de la AABE. } \\
\text { - Destinado a financiar el Paseo del Bajo. }\end{array}$ \\
\hline Manzana IQ & Venta & $\begin{array}{l}\text { - Enajenación por la Corporación Antiguo Puerto Madero. } \\
\text { - Subasta a cargo de la AABE. } \\
\text { - Destinado a financiar el Paseo del Bajo. }\end{array}$ \\
\hline $\begin{array}{l}\text { Dorrego (Plaza } \\
\text { Clemente y Mer- } \\
\text { cado El Dorrego) }\end{array}$ & $\begin{array}{l}\text { Venta y conce- } \\
\text { sión }\end{array}$ & $\begin{array}{l}\text { - Subasta a cargo de la AABE. } \\
\text { - Destinado a financiar obras de la Plaza Clemente, Instituto de la } \\
\text { Vivienda de la Ciudad y mejoramiento del barrio de Colegiales. }\end{array}$ \\
\hline
\end{tabular}

Ivana Socoloff, Nicole Camji, Federico Montagna, María A. Peralta, Yamila L. Sahakian 


\begin{tabular}{|c|c|c|}
\hline Caso & Tipo & Instrumento y destino de los fondos recaudados \\
\hline Distrito Joven & $\begin{array}{l}\text { Construcción y } \\
\text { concesión - polí- } \\
\text { tica de distritos }\end{array}$ & $\begin{array}{l}\text { - Gestión del poder ejecutivo de la Ciudad de Buenos Aires, con } \\
\text { intervención del Consejo del Plan Urbano Ambiental. } \\
\text { - Entre el } 20 \% \text { y el } 50 \% \text { será destinado a la materialización } \\
\text { de las obras (espacios verdes públicos, la infraestructura y la } \\
\text { materialización del Camino de Sirga). }\end{array}$ \\
\hline Parque Thays & Concesión & $\begin{array}{l}\text { - Gestión del poder ejecutivo de la Ciudad de Buenos Aires. } \\
\text { - Concesión o adjudicación de permisos de ocupación, uso y } \\
\text { explotación. }\end{array}$ \\
\hline Plaza Houssay & Concesión & $\begin{array}{l}\text { - Gestión del poder ejecutivo de la Ciudad de Buenos Aires. } \\
\text { - Concesión para diseño, construcción, mantenimiento, } \\
\text { administración y explotación. }\end{array}$ \\
\hline $\begin{array}{l}\text { Zoológico/ } \\
\text { Ecoparque }\end{array}$ & Concesión & $\begin{array}{l}\text { - Gestión del poder ejecutivo de la Ciudad de Buenos Aires. } \\
\text { - Los cánones serán destinados al proceso de transformación } \\
\text { progresiva del Jardín Zoológico y al sostenimiento de los } \\
\text { predios existentes. }\end{array}$ \\
\hline UT Di Tella & Permiso de uso & $\begin{array}{l}\text { - Autorización por la Legislatura porteña. } \\
\text { - Contraprestación por parte de la Universidad mediante becas } \\
\text { educativas a funcionarios y el permiso de uso a vecinos de las } \\
\text { instalaciones del predio. }\end{array}$ \\
\hline
\end{tabular}

Fuente: elaboración de los autores con base en información legislativa.

\section{La enajenación de tierras del Estado Nacional por medio de la Agencia de Administración de Bienes del Estado}

En este apartado, analizaremos las estrategias de enajenación de parcelas pertenecientes al Estado Nacional ubicadas en la Ciudad de Buenos Aires, donde ha intervenido la Agencia de Administración de Bienes del Estado (AABE) en la gestión y concreción de las transacciones. Este organismo público fue creado en el año 2012 por medio de un decreto del poder ejecutivo nacional (encabezado en ese momento por Cristina Fernández de Kirchner), con el objetivo de constituirse en "órgano rector, centralizador de toda la actividad de administración de bienes muebles e inmuebles del Estado Nacional, ejerciendo en forma exclusiva su administración, cuando no corresponda a otros organismos estatales" (Decreto 1382/2012). No obstante, con la llegada de Mauricio Macri a la Presidencia en diciembre de 2015 , se produjo un quiebre en la función de este organismo: en 2016, el poder ejecutivo otorgó mediante decreto la potestad a la AABE para enajenar inmuebles del Estado Nacional sin previa autorización del Congreso de la Nación. 
14 Barrio del área norte de la Ciudad de Buenos Aires, lindero al centro financiero, caracteristico por ser un área nodal del transporte ferroviario hacia la zona metropolitana, por su zona residencial de alta categoría y de alto valor arquitectónico, $y$ por albergar a uno de los asentamientos precarios más grandes de la ciudad, la Villa 31 y 31 bis.

15 Barrio del área norte de la Ciudad de Buenos Aires, fundamentalmente residencial $y$ de esparcimiento, que cuenta con vastas extensiones de espacios verdes. Desde hace más de una década, la inversión privada en el rubro inmobiliario y en emprendimientos culturales $y$ recreativos ha producido un fuerte impacto en este barrio, convirtiéndose en una de las zonas más valorizadas de la ciudad.

\section{territarias 43}

Existe una controversia en torno a la constitucionalidad de la modificación a la función de la AABE introducida en 2016. Los representantes del poder ejecutivo nacional afirman estar amparados por una ley del año 1981, sancionada durante la última dictadura militar en Argentina, que, según afirman distintas organizaciones de la sociedad civil, fue derogada implícitamente en la reforma constitucional de 1994, donde se estableció que la facultad de disponer el uso y la enajenación de los inmuebles del Estado Nacional correspondía al Congreso de la Nación.

A pesar de esta polémica, tras el decreto presidencial de 2016 la AABE atravesó una reestructuración interna que ordenó la institución en torno a cuatro ejes: 1) enajenación de inmuebles; 2) reasignación de usos o redistribución de tierras entre instituciones del Estado; 3 ) revisión y renegociación de concesiones a título oneroso o gratuito; y 4) alianzas con el sector privado para el desarrollo de emprendimientos en las parcelas públicas. El organismo realizó a su vez el Registro Nacional de Bienes Inmuebles del Estado, un listado exhaustivo de todos los inmuebles que conforman el patrimonio del Estado Nacional, información que hasta ese momento se encontraba descentralizada y dispersa entre diversos organismos estatales de los distintos niveles de gobierno. Este trabajo de relevamiento sistemático, de carácter inédito en Argentina, introduce una tecnología novedosa de control del patrimonio nunca antes desplegada con el objetivo explícito de enajenar propiedades del Estado.

De esta manera, a partir de 2016 todo acto de disposición de inmuebles de propiedad del Estado Nacional, cualquiera sea su jurisdicción de origen, debe ser centralizado por la AABE. Entre agosto de 2016 y abril de 2018 se autorizó la convocatoria a subasta de 111 bienes inmuebles ubicados en el territorio nacional y en el exterior, 60 de los cuales se encuentran ubicados en la Ciudad de Buenos Aires (el equivalente al $54 \%$ de las parcelas enajenadas, ver tabla 2). Para septiembre del año 2018, 26 de las 111 parcelas ya habían sido vendidas.

En la Ciudad de Buenos Aires, el parque de activos en venta es sumamente heterogéneo, ya que cuenta con terrenos cuyas dimensiones van de los $30 \mathrm{~m}^{2}$ hasta casi 2 hectáreas. Destacamos que no solo la ciudad capital concentra la mayor cantidad de inmuebles puestos a la venta en el período analizado ( $54 \%$ de las 111 propiedades), sino que a su vez estos terrenos se ubican mayormente en dos barrios de la ciudad: Retiro ${ }^{14}$ y Palermo, ${ }^{15}$ con 24 y 14 inmuebles, respectivamente. La concentración de los inmuebles en estos dos barrios representa más del $60 \%$ del total de inmuebles en venta por medio de la AABE de la Ciudad de Buenos Aires. Así mismo, la mayor parte de los terrenos públicos ya vendidos o concesionados hasta septiembre de 2018 están también ubicados en la Ciudad de Buenos Aires, lo cual habla del alto interés de las autoridades en 
Tabla 2. Decretos de venta de tierras por parte del poder ejecutivo nacional 2015-2018

\begin{tabular}{|c|c|c|c|c|c|c|}
\hline $\begin{array}{c}\text { Decreto/ubicación } \\
\text { de inmuebles }\end{array}$ & Fecha & $\begin{array}{c}\text { Ciudad de } \\
\text { Buenos Aires }\end{array}$ & $\begin{array}{c}\text { Provincia de } \\
\text { Buenos Aires }\end{array}$ & $\begin{array}{c}\text { Resto del } \\
\text { país }\end{array}$ & Extranjero & Total \\
\hline $952 / 16$ & $19 / 08 / 2016$ & 13 & 4 & - & - & 17 \\
\hline $1064 / 16$ & $05 / 10 / 2016$ & 11 & 10 & 4 & 8 & 33 \\
\hline $1173 / 16$ & $15 / 11 / 2016$ & 1 & 1 & 1 & - & 3 \\
\hline $225 / 17$ & $03 / 04 / 2017$ & 26 & 4 & 9 & - & 39 \\
\hline $928 / 17$ & $10 / 11 / 2017$ & 3 & 4 & 5 & - & 12 \\
\hline $355 / 18$ & $23 / 04 / 2018$ & 6 & - & 1 & - & 7 \\
\hline Total & & 60 & 23 & 20 & 8 & 111 \\
\hline
\end{tabular}

Fuente: elaboración de los autores con base en información del poder ejecutivo.

enajenar aquellos inmuebles económica y simbólicamente más valiosos.

\section{Elementos para pensar las racionalidades de la disposición de tierras}

Una multiplicidad de discursos se ha desplegado para fundamentar los proyectos de concesión y privatización del suelo de la Ciudad de Buenos Aires en curso desde 2015. Hemos identificado las siguientes líneas temáticas en los discursos orientados a construir el problema de la gestión y racionalización del suelo porteño: a) la ociosidad o subutilización de las parcelas mercantilizadas; b) la enajenación de las tierras como oportunidad para el desarrollo económico y la financiación de obras públicas, en particular en el sur de la ciudad; c) la promoción a la participación público-privada; d) la puesta en valor del espacio público de la ciudad y la recualificación urbana; y e) la preservación de la identidad urbana y el urbanismo sustentable.

En primer lugar, la racionalización del suelo público de la ciudad es presentada como forma de reparación al diagnóstico de subutilización de las parcelas en el presente y frente al potencial de utilidad que podrían alcanzar en el futuro. Fuera de la órbita de lo público donde esas tierras — según se afirma- "no se necesitan", el suelo devenido en recurso recobraría su utilidad óptima. Así, se sostenía "que existe una importante cantidad de bienes inmuebles dentro del universo en uso, desafectados y concesionados, que al momento se hallan subutilizados o sin destino útil en las diferentes jurisdicciones dependientes del Estado Nacional, resultando menester la optimización de su gestión” (AABE, Resolución 98/2016). 
Conjuntamente al diagnóstico de 'ociosidad y subutilización', las parcelas en venta o concesión son presentadas como áreas degradadas, desaprovechadas o vacantes, para las cuales se propone la privatización como estrategia para su recualificación. Por ejemplo, la zona costera fue descrita como "sin vida ni movimiento" en la presentación del proyecto de Distrito Joven, y su concesión a privados fue presentada como "un resurgimiento para darle un nuevo aire innovador" (audiencia pública, 19 de abril de 2016).

En segundo lugar, los proyectos de concesión y privatización del suelo público desde 2016 a su vez han sido fundamentados por distintas autoridades como grandes 'oportunidades' económicas, inmobiliarias y de financiamiento de la obra pública. Dos tipos de discursos han apuntalado esta línea de argumentación: por un lado, el fomento al crecimiento económico y la dinamización del mercado en zonas determinadas de la ciudad; y, por el otro, el financiamiento de grandes obras de infraestructura y vivienda a partir de la enajenación de los inmuebles públicos. Nuevamente, el proyecto de Distrito Joven sirve de expresión para el primer tipo de discursividad, ya que de él se ha afirmado que generaría "un crecimiento económico general, no solamente para los locales bailables y los sectores gastronómicos que van a estar involucrados, sino también para el turismo externo y para la comunidad de la región que se vería muy fortalecida territarias 43 14 "incubadora de emprendimientos" (audiencia pública, 19 de abril de 2016).

De la misma forma, ciertos proyectos de concesión y privatización del suelo público incluyeron disposiciones acerca del destino de la riqueza económica que se obtendrá por la enajenación de las parcelas, como mencionamos anteriormente. En los casos en que el proyecto fue planteado de esta forma, las autoridades se concentraron en determinadas áreas, sobre la base de un supuesto "pensamiento estratégico de la ciudad" al proponer conjuntamente distintas vías de explotación y desarrollo de zonas determinadas de la ciudad, que generasen una sinergia entre las obras realizadas, o bien entre ellas y los usos preexistentes en esas parcelas. En esta categoría podemos destacar los proyectos de: a) Empalme Norte y Manzana IQ, dos parcelas ubicadas en el barrio de Puerto Madero cuya enajenación contribuiría al financiamiento de la construcción del Paseo del Bajo; b) el proyecto de Tiro Federal, histórico campo de tiro deportivo del barrio de Núñez cuya venta financiaría las obras de reurbanización de la Villa 31 y 31bis en Retiro (también en la zona norte de la ciudad); c) y el de Villa Olímpica, proyecto de nuevas viviendas en el barrio de Villa Soldati cuya enajenación apoyaría económicamente el proceso de reurbanización de la Villa 20, asentamiento precario ubicado a metros de distancia.

En tercer lugar, se destaca en los discursos predominantes sobre la racionalización del suelo porteño la generación 
de proyectos de articulación entre el sector público y el privado. En estos proyectos, el Estado es presentado como garante de las actividades e inversiones de capital del sector privado, asumiendo el riesgo económico e interviniendo en favor del funcionamiento y dinamización del mercado. Los proyectos de concesión y privatización se proponen generar activamente emprendimientos inmobiliarios rentables para el sector privado: es el caso del megaemprendimiento del Autódromo de Buenos Aires, el cual se plantea el objetivo de crear "un desarrollo comercial conexo a la actividad deportiva que permita la instalación en parte del predio del Autódromo [...] de locales comerciales, empresas e industrias relacionadas con el automovilismo y motociclismo, en todas sus variantes" (Plan Integral para la Recuperación del Autódromo, Ley 5732, artículo $2^{\circ}$ ).

Sobre la cuarta cuestión - la puesta en valor del espacio público- observamos que este suele ser representado por las autoridades como el lugar imbuido de neutralidad donde se encuentran sujetos iguales que entablan relaciones sociales imbuidas de civismo. ${ }^{16}$ De esta forma, las autoridades plantean dos ideas en tensión: por un lado, manifiestan la pretensión de crear nuevos espacios públicos y generar vida social dentro de los parámetros considerados deseables y legítimos; $y$, por otro, afirman que la puesta bajo dominio privado de las tierras públicas de la ciudad es el medio adecuado para realizarlo. Esta dimensión fue expresada de la siguiente manera a propósito del proyecto de Plaza Houssay: "De este modo, la concesión de obra pública, que el presente proyecto de ley propicia autorizar, apunta al desarrollo del espacio referido orientado a mejorar la interacción social, fomentar el desarrollo barrial, incrementar el aspecto cultural, mientras se preserva el medio ambiente, y generando en consecuencia un foco de actividad social, cultural y gastronómico que atraiga a las personas a la Plaza Dr. Bernardo A. Houssay" (mensaje de elevación al recinto, 29 de octubre de 2015).

Finalmente, ciertos discursos de las autoridades pueden ser enmarcados en el paradigma del urbanismo sustentable, herramienta de planeamiento urbano que, desde la intervención en lo ambiental, lo social y lo económico, se orienta a transformar a las metrópolis que han experimentado un crecimiento desorganizado y que, en dicho proceso, han perdido identidad, funcionalidad y valor estético (Hernández Moreno, 2008). Esta forma contemporánea de planeamiento urbano contempla cuestiones de calidad arquitectónica, diseño, conectividad, movilidad, diversidad y equilibrio en los usos del suelo. Desde la perspectiva del urbanismo sustentable se pretende recuperar, fortalecer o preservar la identidad de un lugar de la ciudad, en este caso, por medio de la mercantilización de tierras públicas y de emprendimientos inmobiliarios rentables. A modo de ejemplo, pueden destacarse el objetivo de promover buenas prácticas
${ }^{16}$ Puede verse sobre esto el texto de Delgado Ruiz y Malet (2007). 
ambientales por parte de los negocios instalados en el Distrito Joven; el propósito de "desarrollo equilibrado, integrado e inclusivo (locución en la Sesión Ordinaria de la Legislatura del 24 de noviembre de 2016)" sostenido por las autoridades respecto al proyecto de la Villa Olímpica; la intención de "realzar las características académicas que le dan identidad" (mensaje de elevación al recinto, 29 de octubre de 2015) a la Plaza Houssay — ubicada frente a las facultades de Ciencias Médicas y de Ciencias Económicas de la Universidad de Buenos Aires-; y la determinación de "sostener esas tierras que desde hace más de sesenta años son un autódromo para que siga habiendo un autódromo" (locución en la Sesión Ordinaria de la Legislatura del 7 de diciembre de 2016) en la parcela del sur de la ciudad.

\section{Conclusiones}

En este artículo nos hemos propuesto analizar las estrategias de disposición de tierra desplegadas por las autoridades en el ámbito de la Ciudad de Buenos Aires desde 2015, a fin de comprender las modalidades que adoptan estas estrategias y las racionalidades sobre las cuales se sustentan. A partir del análisis realizado, hemos podido constatar que el proceso de disposición de tierras públicas en curso desde el año 2015 comprende una importante cantidad de parcelas destinadas a proyectos inmobiliarios, muchos de los cuales son de gran envergadura e implican intervenciones de gran escala, como los llamados 'megaemprendimientos'. Destacamos como rasgos distintivos de este proceso la ubicación céntrica de la mayoría de los terrenos puestos a disposición y la celeridad con que las autoridades han procedido en la enajenación de estas tierras para el sector privado.

A su vez, a partir del repaso bibliográfico por estudios realizados en otras latitudes, hemos observado que la privatización/mercantilización de tierra ocurrida en la Ciudad de Buenos Aires muestra estrecha similitud con lo que sucede en otras geografías, lo cual es explicable sin duda por fenómenos de carácter más estructural como la profundización/inflexión desigual y combinada en el neoliberalismo urbano en el marco de la financiarización de la producción urbana, que ha convertido a la tierra en un nuevo asset class. Si bien este proceso muestra múltiples especificidades en nuestro país y en la ciudad de Buenos Aires (Socoloff, 2019), se encuentra atravesado por lógicas de carácter global.

A partir del análisis del contenido de los discursos orientados a dotar de sentido a la disposición de bienes inmuebles del Estado, hemos mostrado la utilización de criterios de 'racionalización' del espacio físico frente al diagnóstico de 'ociosidad' y 'subutilización' de los inmuebles por parte del Estado. En los discursos analizados, la tierra y los bienes inmuebles son entendidos como recursos económicos para ser explotados de forma eficiente, es decir, aprovechando toda su 'potencialidad' 
económica. Fuera de la órbita de lo público, donde no serían 'necesarios', se afirma que la tierra recobrará su utilidad óptima.

En cuanto a los dispositivos, hemos dado cuenta de dos fenómenos interrelacionados. Por un lado, y en cierta continuidad con lo que ocurriera en la década de los noventa, la creación de organismos públicos (como la Agencia de Bienes Sociedad del Estado), de entidades directamente paraestatales (como el fideicomiso a cargo del Autódromo) o de zonas de normativa particular (Distrito Joven) muestran el uso de la creatividad institucional para disponer de tierras públicas en la ciudad sin participación plena de la Legislatura. Así mismo, y como hemos mostrado, la fragmentación presupuestaria y urbana que implican estos proyectos emerge como otro fenómeno propio de estas estrategias de disposición.

Por otro lado, observamos un avance de la tecnología en manos del sector público al servicio de la mercantilización del suelo a partir de la transformación de las funciones de la AABE. Dicha tecnología, así como la información producida, se ha puesto a disposición de los agentes del sector inmobiliario, quienes participaron activamente de todo el proceso de toma de decisiones, como pudimos verificar en diversas observaciones en actividades del sector (Socoloff, 2019). Esta tecnología ha permitido ordenar los títulos de propiedad, la mensura de los terrenos, así como acelerar todos los trámites de traspaso de titularidad. Igualmente, no resulta un detalle menor la centralización de la gestión o disposición de la tierra en manos de una agencia nacional, sino que es parte de una lógica de control 'desde Buenos Aires', ciudad donde se encuentra emplazada la AABE y donde se realizan las subastas del patrimonio estatal de todas las provincias del país.

Finalmente, resta una reflexión en torno a la inflexión del neoliberalismo urbano para el caso de la Ciudad de Buenos Aires en estos procesos analizados. Desde nuestro punto de vista, y en continuidad con lo observado en trabajos anteriores sobre los distritos en la Ciudad de Buenos Aires (Socoloff, 2013b, 2017), la planificación urbana neoliberal actual no solamente se propondría atender a la cuestión de la austeridad en el gasto, sino que las autoridades estarían orientadas en mayor medida a organizar y garantizar la ganancia del sector privado. Las modalidades en este caso, como dijimos, serían la transferencia de tierra centralmente ubicada para promover las inversiones inmobiliarias, el mejoramiento de los sistemas de información, el ordenamiento de los títulos de propiedad, la asistencia técnica a los desarrolladores en todo el proceso de subasta y el aceleramiento de los procedimientos.

Por lo aquí expuesto, sostenemos que la 'ciudad de los negocios' a la que se referían los pensadores en la década de los noventa parece estar convirtiéndose en la actualidad en una 'ciudad para los negocios' donde, sin embargo, la tierra territarias 43 17 
pública - como dadora de vida-continúa en permanente disputa.

\section{Referencias}

Arqueros Mejicas, S., \& González Redondo, C. (2017). La política de distritos del sur de Buenos Aires: una mirada en perspectiva. Quid, 16(6). https://publicaciones.sociales.uba.ar/index.php/ quidl6/article/view/2851/pdf_7

Baer, L. (2011). El mercado de suelo formal de la Ciudad de Buenos Aires en su contexto metropolitano. Dinámica de precios de terrenos, desarrollo inmobiliario y acceso a la vivienda en la década de dos mil (Facultad de Filosofía y Letras, Área Geografía, Universidad de Buenos Aires).

Baer, L., \& Kauw, M. (2016). Mercado inmobiliario y acceso a la vivienda formal en la Ciudad de Buenos Aires, y su contexto metropolitano, entre 2003 y 2013. EURE, 42(126). https://doi.org/10.4067/S025071612016000200001

Beswick, J., \& Penny, J. (2018). Demolishing the present to sell off the future? The emergence of 'financialized municipal entrepreneurialism' in London. International Journal of Urban and Regional Research, 42(4), 612-632. https://doi.org/10.1111/1468 2427.12612

\section{tersitarias 43}

1960-2000. Review of International Political Economy, 11(3), 447-488. https://doi.org/10.1080/096922 9042000282864

Christophers, B. (2017). The State and financialization of public land in the United Kingdom. Antipode, 49, 62-85. https://doi.org/10.1111/anti.12267

Christophers, B. (2018). The new enclosure. The apropiation of public land in neoliberal Britain. Verso.

Ciccolella, P., \& Mignaqui, I. (2008). Metrópolis latinoamericanas: fragilidad del Estado, proyecto hegemónico y demandas ciudadanas. Algunas reflexiones a partir del caso de Buenos Aires. Cuadernos del Cendes, 25(69), 47-68.

Ciccolella, P., \& Vecslir, L. (2012). Dinámicas, morfologías y singularidades en la reestructuración metropolitana de Buenos Aires. Revista Iberoamericana de Urbanismo, (8), 23-41. https://upcommons.upc.edu/handle/2099/13014

Clichevsky, N. (1996). Politica social urbana: normativa y configuración de la ciudad. Espacio.

Cravino, M. C., Fernández Wagner, R., \& Varela, O. (2000). Notas sobre la política habitacional en el Área Metropolitana de Buenos Aires en los años noventa. En Actas de las jornadas preparatorias del seminario internacional "Las regiones metropolitanas del Mercosur y México: entre la competitividady la complementariedad”. UNGS. http:// 
biblioteca.municipios.unq.edu.ar/modules/mislibros/archivos/notas-.pdf

De Marinis, P. (1999). Gobierno, gubernamentalidad, Foucault y los anglofoucaultianos (Un ensayo sobre la racionalidad política del neoliberalismo). En F. García Selgas y R. Ramos Torre (Eds.), Retos actuales de la teoría social: globalidad, reflexividad y riesgo (pp. 73-103). Centro de Investigaciones Sociológicas.

Delgado Ruiz, M., \& Malet, D. (2007). El espacio público como ideología. Jornadas Marx siglo XXI. Universidad de la Rioja. https://antropologiadeoutraforma.files.wordpress.com/2014/03/ el-espacio-pc3bablico-como-ideologc3ada-manuel-delgado.pdf

Del Río, J. P., Landarg, F., \& Arturi, D. (2014). La impronta del mercado inmobiliario en el período neodesarrollista. Realidad Económica, 77-101. http://www.iade.org.ar/articulos/ la-impronta-del-mercado-inmobiliarioen-el-periodo-neodesarrollista

Fernández, R., \& Aalbers, M. (2019). Housing financialization in the global South: in search of a comparative framework. In Housing policy debate (in press). https://doi.org/10.1080 /10511482.2019.1681491

Fields, D. (2013). From property abandonment to predatory equity: writings on financialization and urban space in New York city. https://academicworks. cuny.edu/gc_etds/2167
Fix, M. (2012). Nuevas fronteras inmobiliarias. El caso de la operación urbana Faría Lima. En B. Cuenya, P. Novais \& C. Vainer (Comps.), Grandes proyectos urbanos. Miradas criticas sobre la experiencia argentina y brasilera (pp. 331-376). Café de las Ciudades.

Foucault, M. (2008). Nacimiento de la biopolitica. Fondo de Cultura Económica de Argentina.

Garay, A. (2004). La rehabilitación de las áreas céntricas: el caso de Buenos Aires. En M. E. Martínez Delgado (ed.), El centro histórico: objeto de estudio e intervención. Editorial Pontificia Universidad Javeriana.

Garay, A. (2007). On the administration of urban projects: the lessons of Puerto Madero. In J. F. Liernur (Ed.), Case: Puerto Madero waterfront. Harvard University Graduate School of DesignPrestel.

Guevara, T. (2013). ¿La ciudad para quién? Transformaciones territoriales, políticas urbanas y procesos de producción del hábitat en la ciudad de Buenos Aires (1996-2011) (Tesis doctoral en Ciencias Sociales, Universidad de Buenos Aires).

Harvey, D. (1982). The limits to capital. Blackwell.

Harvey, D. (1989). From managerialism to entrepreneurialism: the transformation in urban governance in late capitalism. Human Geography, 71, 3-17. https:// doi.org/10.2307/490503 territarios 43

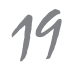


Hernández Moreno, S. (2008). Introducción al urbanismo sustentable o nuevo urbanismo. Revista Espacios Públicos, 11(23), 298-307. http://www.redalyc. org/pdf/676/67611217015.pdf

Mignaqui, I. (2010). La Corporación Buenos Aires Sur, una estrategia de desarrollo inconclusa. En M. Gutman (Coord.), Argentina: persistencia y diversificación, contrastes e imaginarios en las centralidades urbanas, Vol. 3. OLACCHI.

Mignaqui, I. (2012). Planes y proyectos territoriales. Escenarios de la metrópolis planificada. Revista Iberoamericana de Urbanismo, (8), 121-137. https:// upcommons.upc.edu/bitstream/ handle/2099/13038/08_08_Mignaqui.pdf? sequence $=1$

Murray Li, T. (2014). What is land? Assembling a resource for global investment. Trans Inst $\mathrm{Br}$ Geogr., 589-602). https://doi.org/10.1111/tran.12065

Pedersen, R. H. (2016). Access to land reconsidered: the land grab, polycentric governance and Tanzania's new wave land reform. Geoforum, (72), 104-113. https://doi.org/10.1016/j. geoforum.2015.12.010

Pedersen, R. H., \& Buur, L. (2016). Editorial Beyond land grabbing. Old morals and new perspectives on contemporary investments. Geoforum, (72), 77-81. https://doi.org/10.1016/j.geoforum.2016.03.013

territarias 43 20
Aires. Economia, Sociedad y Territorio, $V I(21), 31-54$. https://est.cmq. edu. $\mathrm{mx} /$ index.php/est/article/ view/272/733

Shatkin, G. (2017). Cities for profit: the real estate turn in Asia's urban politics. Cornell University Press.

Socoloff, I. (2013a). Reflexiones en torno a las relaciones entre empresa, Estado $y$ ciudad: un estudio a partir del caso IRSA en Buenos Aires (1991-2012) (Tesis doctoral en Ciencias Sociales, Facultad de Ciencias Sociales, Universidad de Buenos Aires).

Socoloff, I. (2013b). Polos, distritos y enclaves en Buenos Aires. De la pedagogía del inversor a la "inflación" de los precios del suelo. En J. Marín (Comp.), La ciudad empresa. Centro Cultural de la Cooperación.

Socoloff, I. (2015). La crisis como oportunidad: código y gobierno del suelo en Buenos Aires (1977-2003). En S. Murillo (Coord.), Neoliberalismo y gobiernos de la vida. Diagrama global $y$ despliegues en Argentina y América Latina. Biblos.

Socoloff, I. (2017). Una reflexión sobre los distritos creativos y las mutaciones del empresarialismo urbano porteño. Quid, 16(6). https://publicaciones. sociales.uba.ar/index.php/quidl6/ article/viewFile/2843/pdf_8

Socoloff, I. (2019). Subordinate financialization and housing finance: the case of Indexed Mortgage Loans' Coalition in Argentina. Housing Policy Debate. 
https:// doi.org/10.1080/10511482 .2019.1676810

Theodore, N., Peck, J., \& Brenner, N. (2009). Urbanismo neoliberal: la ciudad y el imperio de los mercados. Temas Sociales, (66), 1-11. http:// www.sitiosur.cl/r.php? id $=898$

Torres, H. (2000). El mapa social de Buenos Aires (1940-1990). Dirección de
Investigaciones, Secretaría de Investigación y Posgrado de la Facultad de Arquitectura y Urbanismo (UBA).

Whiteside, H. (2019). The State's estate: devaluing and revaluing 'surplus' public land in Canada. Environment and Planning A: Economy and Space, 505-526. https://doi. org/10.1177/0308518X17723631

\section{Anexo}

Tabla 1 (ampliada). Disposición de tierra en CABA aprobada por la Legislatura (dic. 2015 a abr. 2018)

\begin{tabular}{|c|c|c|c|c|c|c|}
\hline Caso & Fecha & Ley & Tipo & Descripción & \multicolumn{2}{|c|}{ Instrumento } \\
\hline 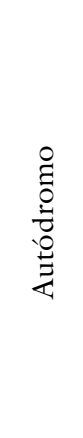 & 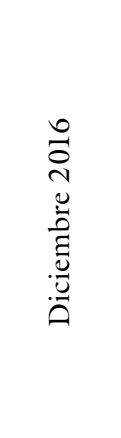 & 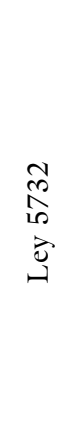 & 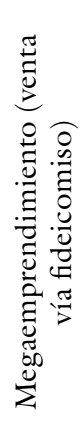 & $\begin{array}{l}\text { Transformación del área con } \\
\text { apertura de calles internas y } \\
\text { la puesta a disposición de esas } \\
\text { tierras para el desarrollo de } \\
\text { emprendimientos inmobiliarios } \\
\text { (hoteles, museos, comerciales, } \\
\text { etc.). El plan de implementación } \\
\text { por etapas: primero invertirá el } \\
\text { GCBA, mientras que los priva- } \\
\text { dos invertirían en dos etapas } \\
\text { siguientes. }\end{array}$ & $\begin{array}{l}\text { Normativa especial } \\
\text { Distrito del Deporte. } \\
\text { Constitución de un } \\
\text { directorio del fideico- } \\
\text { miso que gestiona los } \\
\text { bienes (Gobierno de la } \\
\text { Ciudad, Banco Ciudad, } \\
\text { las entidades del auto- } \\
\text { movilismo participan). }\end{array}$ & $\begin{array}{l}\text { Constitución de fideicomiso } \\
\text { financiero que se constituye } \\
\text { a } 30 \text { años, conformado por } \\
\text { los bienes fideicomitidos por } \\
\text { el Gobierno de la Ciudad } \\
\text { (derechos de uso y hasta } 3 \\
\text { millones de dólares) y por } \\
\text { los inversores, sobre todo } \\
\text { desarrolladores. El Banco } \\
\text { Ciudad actúa como fiduciario. } \\
\text { Los desarrolladores recibirán } \\
\text { ciertos incentivos fiscales. }\end{array}$ \\
\hline 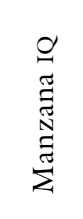 & 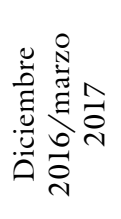 & \begin{tabular}{l}
$\hat{a}$ \\
$\hat{\imath}$ \\
$\vec{\jmath}$ \\
\multirow{1}{*}{}
\end{tabular} & $\stackrel{\Xi}{\stackrel{\Xi}{0}}$ & $\begin{array}{l}\text { Autorización de venta Manzana } \\
\text { IQ (Puerto Madero) por parte de } \\
\text { la AABE para la construcción de } \\
\text { torres. El valor del terreno fue } \\
\text { tasado en US } \$ 90000000 .\end{array}$ & $\begin{array}{l}\text { Realización de la subas- } \\
\text { ta a cargo de la AABE. }\end{array}$ & $\begin{array}{l}\text { Venta para financiar el Paseo } \\
\text { del Bajo. La entidad a la cual } \\
\text { se encargó la enajenación } \\
\text { del inmueble público fue la } \\
\text { Corporación Antiguo Puerto } \\
\text { Madero. }\end{array}$ \\
\hline
\end{tabular}




\begin{tabular}{|c|c|c|c|c|c|c|}
\hline \multirow{2}{*}{ Caso } & \multirow{2}{*}{ Fecha } & \multirow{2}{*}{ Ley } & \multirow{2}{*}{ Tipo } & \multirow{2}{*}{ Descripción } & \multicolumn{2}{|c|}{ Instrumento } \\
\hline & & & & & Gestión & Origen y destino de fondos \\
\hline 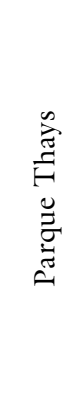 & 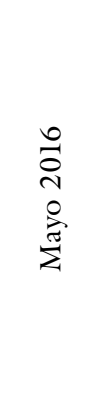 & 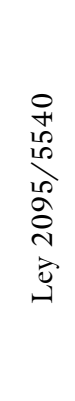 & 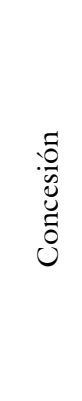 & $\begin{array}{l}\text { Se autoriza al poder ejecutivo a } \\
\text { concesionar el uso y la explota- } \\
\text { ción a un plazo de } 30 \text { años. El } \\
\text { área afectada se delimita entre } \\
\text { las plazas Parque Thays y Plaza } \\
\text { República Federativa de Brasil. } \\
\text { El plan propone la creación de } \\
\text { un centro de exposiciones y } \\
\text { convenciones, para transformar- } \\
\text { se en un centro de reuniones y } \\
\text { negocios. }\end{array}$ & $\begin{array}{l}\text { Poder ejecutivo de } \\
\text { la Ciudad de Buenos } \\
\text { Aires. }\end{array}$ & $\begin{array}{l}\text { Concesión o adjudicación de } \\
\text { permisos de ocupación, uso y } \\
\text { explotación. }\end{array}$ \\
\hline 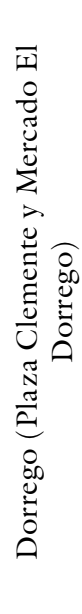 & 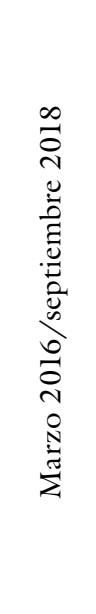 & 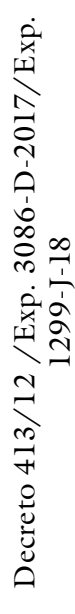 & 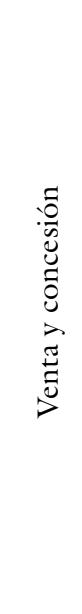 & $\begin{array}{l}\text { Luego de que un decreto auto- } \\
\text { rizara la concesión a } 30 \text { años del } \\
\text { predio ubicado en Dorrego } 1680 \\
\text { del barrio de Colegiales para } \\
\text { la construcción de un 'estacio- } \\
\text { namiento subterráneo vecinal', } \\
\text { las organizaciones vecinales } \\
\text { reclamaron la concreción del } \\
\text { proyecto de la 'Plaza Clemente'. } \\
\text { Para su financiamiento, se decla- } \\
\text { ró "innecesario para la gestión } \\
\text { del Gobierno de la CABA" y } \\
\text { se autorizó la enajenación en } \\
\text { subasta pública el inmueble del } \\
\text { Mercado 'El Dorrego'. } 35 \% \text { área } \\
\text { edificable + 65\% espacio público } \\
\text { con cocheras. }\end{array}$ & $\begin{array}{l}\text { Realización de la subas- } \\
\text { ta a cargo de la AABE. }\end{array}$ & $\begin{array}{l}\text { Venta de los terrenos de El } \\
\text { Dorrego para financiar las } \\
\text { obras de la Plaza Clemente, } \\
\text { IVC y mejoramiento del barrio } \\
\text { de Colegiales. }\end{array}$ \\
\hline 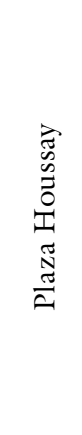 & 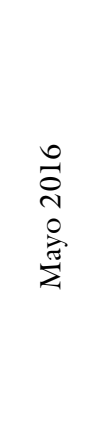 & $\begin{array}{l}2 \\
\text { के } \\
10 \\
10 \\
0 \\
0 \\
0\end{array}$ & 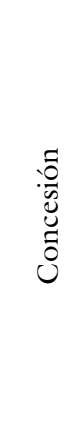 & $\begin{array}{l}\text { Ley } 5539 \text { autoriza al poder } \\
\text { ejecutivo a hacer un llamado a } \\
\text { licitación pública para conce- } \\
\text { siones a } 30 \text { años para el diseño, } \\
\text { construcción, mantenimiento, } \\
\text { administración y explotación, del } \\
\text { centro cultural, gastronómico y } \\
\text { playa de estacionamiento sobre } \\
\text { Plaza Houssay. El programa } \\
\text { arquitectónico se basa en una } \\
\text { modificación y restauración de la } \\
\text { plaza en todos sus niveles. }\end{array}$ & $\begin{array}{l}\text { Poder ejecutivo de } \\
\text { la Ciudad de Buenos } \\
\text { Aires. }\end{array}$ & $\begin{array}{l}\text { Concesión para diseño, } \\
\text { construcción, mantenimiento, } \\
\text { administración y explotación. }\end{array}$ \\
\hline
\end{tabular}




\begin{tabular}{|c|c|c|c|c|c|c|}
\hline \multirow{2}{*}{ Caso } & \multirow{2}{*}{ Fecha } & \multirow{2}{*}{ Ley } & \multirow{2}{*}{ Tipo } & \multirow{2}{*}{ Descripción } & \multicolumn{2}{|c|}{ Instrumento } \\
\hline & & & & & Gestión & Origen y destino de fondos \\
\hline 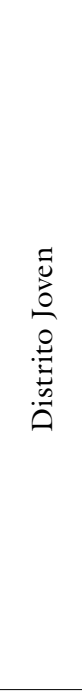 & 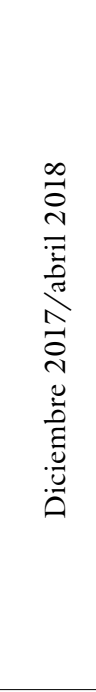 & $\begin{array}{l}5 \\
0 \\
0 \\
0 \\
0 \\
1\end{array}$ & 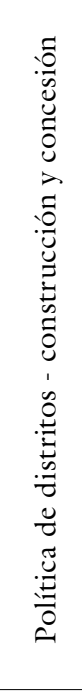 & $\begin{array}{l}\text { Decreto } 647 / 2016 \text { autoriza } \\
\text { adjudicar las concesiones sobre } \\
\text { el predio de Punta Carrasco. } \\
\text { En el año } 2015 \text { se presentó } \\
\text { un proyecto de ley (2464) a la } \\
\text { Legislatura porteña. En } 2017 \\
\text { se aprobó en primera lectura la } \\
\text { creación del distrito, que autori- } \\
\text { za otorgar en concesión del uso } \\
\text { y la explotación de espacios de } \\
\text { dominio público por un plazo de } \\
\text { hasta diez años para destinarlas } \\
\text { al Distrito Joven. También se } \\
\text { autoriza al poder ejecutivo la } \\
\text { construcción en los espacios de } \\
\text { dominio público de la Ciudad de } \\
\text { Buenos Aires sujetos a conce- } \\
\text { sión u otorgamiento de uso y } \\
\text { explotación. }\end{array}$ & $\begin{array}{l}\text { Poder ejecutivo de } \\
\text { la Ciudad de Buenos } \\
\text { Aires, con intervención } \\
\text { del Consejo del Plan } \\
\text { Urbano Ambiental. } \\
\end{array}$ & $\begin{array}{l}\text { Entre el } 20 \% \text { y el } 50 \% \text { deberá } \\
\text { ser destinado a la materiali- } \\
\text { zación de las obras (espacios } \\
\text { verdes públicos, la infraestruc- } \\
\text { tura y la materialización del } \\
\text { Camino de Sirga). }\end{array}$ \\
\hline 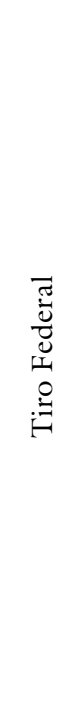 & 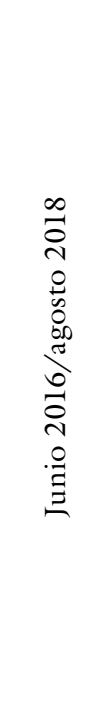 & $\begin{array}{l}\infty \\
10 \\
10 \\
10 \\
2 \\
3 \\
\end{array}$ & 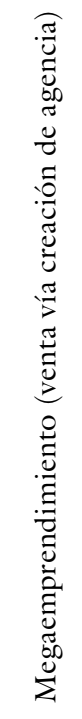 & $\begin{array}{l}\text { 1) Creación 'Agencia de Bienes } \\
\text { de Sociedad del Estado', que } \\
\text { autoriza a vender bienes inmue- } \\
\text { bles de la Ciudad de Buenos } \\
\text { Aires. 2) Se dispone la venta de } \\
168193 \mathrm{~m}^{2} \text { correspondientes a } \\
\text { Tiro Federal: un polígono desti- } \\
\text { nado a la creación del Parque de } \\
\text { la Innovación: un complejo de } \\
\text { oficinas, laboratorios y empresas } \\
\text { integradas a un gran espacio } \\
\text { público. Dos polígonos serán } \\
\text { vendidos. En Av. Libertador se } \\
\text { podrán construir torres, tanto } \\
\text { de viviendas como de oficinas, } \\
\text { se usarán seis hectáreas para } \\
\text { el campus universitario y las } \\
\text { empresas que se quieran mudar } \\
\text { allí, todas ellas del ámbito de la } \\
\text { ciencia y la tecnología. }\end{array}$ & $\begin{array}{l}\text { Creación de una agen- } \\
\text { cia especial para vender } \\
\text { los bienes con autoriza- } \\
\text { ción de la Legislatura. }\end{array}$ & $\begin{array}{l}\text { El } 20 \% \text { de la venta de uno de } \\
\text { los polígonos será destinado a } \\
\text { la urbanización de la Villa } 31 . \\
\text { Se licitará la franja de terreno } \\
\text { que da a Av. Libertador para } \\
\text { financiar el resto de la obra. }\end{array}$ \\
\hline
\end{tabular}




\begin{tabular}{|c|c|c|c|c|c|c|}
\hline Caso & Fecha & Ley & Tipo & Descripción & \multicolumn{2}{|c|}{ Instrumento } \\
\hline 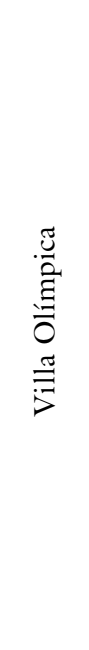 & $\begin{array}{l}0 \\
0 \\
0 \\
0 \\
0 \\
0 \\
0 \\
0 \\
0 \\
0 \\
Z\end{array}$ & 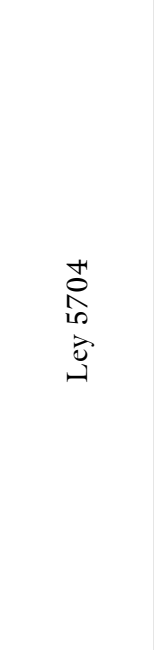 & 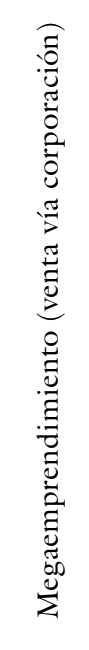 & $\begin{array}{l}\text { 'Urbanización del Parque de } \\
\text { la Ciudad y la Villa Olímpica, } \\
\text { afecta áreas específicas del barrio } \\
\text { de Villa Soldati en la comuna } \\
\text { 8, CABA. El diseño del distrito } \\
\text { correspondiente al área del } \\
\text { Parque de la Ciudad surgirá de la } \\
\text { convocatoria a un concurso pú- } \\
\text { blico, disponiéndose que dentro } \\
\text { del programa de necesidades del } \\
\text { futuro parque se deba incluir un } \\
\text { área de equipamiento deporti- } \\
\text { vo. Se establecen obras para el } \\
\text { Hospital Dra. Cecilia Grierson. } \\
\text { Los predios Villa Olímpica y el } \\
\text { Área de Equipamiento Lacarra } \\
\text { se declaran innecesarios para la } \\
\text { gestión del Gobierno de la CABA. }\end{array}$ & $\begin{array}{l}\text { Desafectación trans- } \\
\text { firiéndose a la Corpo- } \\
\text { ración Buenos Aires } \\
\text { Sur S.E. Desafectación } \\
\text { transfiriéndose al Insti- } \\
\text { tuto de la Vivienda de } \\
\text { la Ciudad; los predios } \\
\text { alojamiento, a los } \\
\text { atletas olímpicos, los } \\
\text { cuales se venderán con } \\
\text { destino vivienda para } \\
\text { vecinos de la comuna } 8 \\
\text { una vez finalizados los } \\
\text { Juegos Olímpicos de la } \\
\text { Juventud } 2018 \text {. }\end{array}$ & $\begin{array}{l}\text { De los fondos recaudados, el } \\
50 \% \text { será ingresado para el } \\
\text { financiamiento y desarrollo } \\
\text { de proyectos de la comuna } 8 \text {. } \\
\text { El } 50 \% \text { restante será para la } \\
\text { urbanización de la Villa } 20 \text {. }\end{array}$ \\
\hline 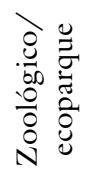 & 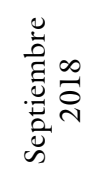 & 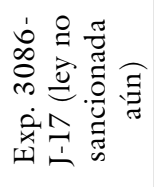 & 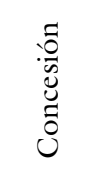 & $\begin{array}{l}\text { Se autoriza la concesión de uso y } \\
\text { explotación de edificios y nuevos } \\
\text { espacios ubicados en el predio } \\
\text { del Jardín Zoológico 'Eduardo } \\
\text { Ladislao Holmberg'. }\end{array}$ & $\begin{array}{l}\text { Poder ejecutivo de } \\
\text { la Ciudad de Buenos } \\
\text { Aires. }\end{array}$ & $\begin{array}{l}\text { Los cánones serán destinados } \\
\text { al proceso de transformación } \\
\text { progresiva del Jardín Zooló- } \\
\text { gico y al sostenimiento de los } \\
\text { predios existentes. }\end{array}$ \\
\hline
\end{tabular}

Fuente: elaboración de los autores con base en información legislativa. 